\title{
The vegetation recovery pattern and affecting factors after pipeline disturbance in northwest China
}

\author{
Jun Xiao ${ }^{\mathrm{a}, \mathrm{b}}$, Peng Shi ${ }^{\mathrm{c}}$, Yafeng Wang ${ }^{\mathrm{a}}$, Lei Yang ${ }^{\mathrm{a}, *}$ \\ a State Key Laboratory of Urban and Regional Ecology, Research Center for Eco-Environmental Sciences, Chinese Academy of Sciences, Beijing 100085, China \\ ${ }^{\mathrm{b}}$ Key Laboratory of Agro-ecological Processes in Subtropical Region, Institute of Subtropical Agriculture, Chinese Academy of Sciences, Changsha 410125, \\ China \\ ${ }^{c}$ Key Laboratory of Northwest Water Resources and Environment Ecology of Ministry of Education, Xi'an University of Technology, Xi'an 710048, China
}

\section{A R T I C L E I N F O}

\section{Article history:}

Received 18 June 2015

Received in revised form

21 December 2015

Accepted 21 December 2015

\section{Keywords:}

Affecting factors

Buffer analysis

Engineering factor

Environment factor

Recovery period

Pipeline construction

\begin{abstract}
A B S T R A C T
Pipeline construction has severe disturbance on local ecosystems, especially in arid and semi-arid regions. Vegetation recovery along the pipeline is crucial for ecosystem management and eco-environment restoration. In this study, three typical regions with different backgrounds and engineering characteristics in northwest China were selected to analyze vegetation recovery pattern after pipeline disturbance by using comparative analysis and RDA analysis. The results showed that vegetation condition in the zone $10 \mathrm{~m}$ from the pipeline was worse than construction area above the pipeline, and was identified as a key area in which vegetation restoration needs to occur. Rainfall and total sunshine duration were found to be key factors affecting vegetation recovery. Additionally, recovery duration also played important roles in vegetation recovery. The affecting factors can be divided into two categories: environmental factors; and, engineering factors. Environmental factors contribute more to the differences of vegetation in different regions, while the engineering factors may play a more important role in relation to vegetation recovery within a region. In general, the effects of pipeline construction on vegetation pattern were confined to $300 \mathrm{~m}$ from the pipeline based on this study. However, artificial measures may hasten the vegetation recovery process. This research could provide scientific guidance for ecological restoration and environmental management for the construction of linear projects.
\end{abstract}

(c) 2015 Elsevier GmbH. All rights reserved.

\section{Introduction}

Pipelines are widely used for long-distance goods transportation (Olson \& Doherty, 2012), and have several advantages (e.g., high transport volume, high security, and low energy consumption) over traditional transportation methods such as roads or railways (Howgego \& Roe, 1998; Liu, Noble, Wu, \& Zuniga, 1998; Egbunike \& Potter, 2011). However, pipelines inevitably introduce human disturbances to the local ecosystems along the pipelines routes (Yang et al., 2010; Yakovleva, 2011). In the construction stage, surface vegetation is usually removed for ditch excavation and road paving (Malizia, Chacoff, Grau, \& Brown, 2004), followed by backfilling and compaction. The influx of vehicles and workers also affects the environment in the working area. Unsurfaced roads may sometimes be maintained as accompanying roads (Twort \& Rees, 2004). Pipeline construction often alter the local soil and hydrologi-

\footnotetext{
* Corresponding author.

E-mail address: leiyang@rcees.ac.cn (L. Yang).
}

cal properties (Hopmans \& Dane, 1986; Ivey \& McBride, 1999; Soon, Arshad, Rice, \& Mills, 2000), introduce new species, alter the plant community (Olson \& Doherty, 2012), and cause habitat fragmentation (Andrews 1992; Yang et al., 2010). The changes in vegetation and plant community may be easily observed after backfilling. Evaluating the vegetation condition after pipeline construction is very useful in understanding vegetation recovery processes and decision-making on pipeline management.

Because of the large spatial extent of pipeline projects, natural vegetation recovery is the most economical method of ecosystem recovery (Bradshaw, 1997). This method is most often used, with the exclusion of some special protected areas that need to take practical restoration measures (Ma et al., 2012a; Ma et al., 2013). Most disturbances to the surrounding environment occur mainly in the constructing period. During pipeline operation, the intensity of human activity decreases to a low level when the plant community may recover gradually (Martínez-Ruiz, Fernández-Santos, Putwain, \& Fernández-Gómez, 2007), called the "recovery period". The initial stage of pipeline operation is important to vegetation recovery and there has been increasing recognition of the signifi- 
cance of this period (Hann et al., 2005; McMahan, Arnold, Powell, Welsh, \& Donnelly, 2008a; Desserud, Gates, Adams, \& Revel, 2010). Many studies have investigated the factors affecting vegetation recovery after pipeline construction (Malizia et al., 2004; Bayramov, Buchroithner, \& McGurty, 2011).

By the end of $2011,91,000 \mathrm{~km}$ of pipeline was in place throughout China, and roughly $50,000 \mathrm{~km}$ more are to be constructed in the near future (Industry Research Center 2014). The West-East Gas Pipelines (WEGP) and the Western Crude Oil Pipeline (WCOP) were constructed at the beginning of the 21st century aiming to transport natural gas and oil from western to eastern China (Kambara \& Howe, 2007; Chen, Tian, Zhang, Feng, \& Yang, 2012). These pipeline projects pass through various kinds of ecological regions and have already resulted in many environmental effects, e.g. soil erosion, land desertification, habitat fragmentation, and vegetation destruction (Chen \& Gao, 2006). How the environmental effects in different areas are to be managed with the rapid development of pipeline projects in China have been the focus of studies (Wang, Xie, Li, \& Zhu, 2010; Qi, Hao, Ouyang, \& Cheng, 2012). However, studies on vegetation recovery after pipeline construction in western China are still lacking. In this study, three typical regions along the longdistance pipelines were selected and five vegetation indices were used to identify the vegetation recovery pattern and their affecting factors after the pipeline disturbance; field survey on plant feature with buffer and transect method were used. We assumed that during the construction period, vegetation condition of the affected areas was worst, and after this period, natural recovery started and vegetation condition was gradually getting better. The vegetation recovery patterns in different regions and their affecting factors were analyzed. The objectives of this study were to: (1) investigate the recovery pattern of vegetation after pipeline construction in the semi-arid and arid regions in northwestern China; (2) identify the difference in vegetation recovery between regions; and, (3) analyze the roles of environmental factors and engineering factors in vegetation recovery.

\section{Methods}

\subsection{The study area}

Three typical regions along the WEGPs and WCOP in northwestern China were selected as case study area (Fig. 1). These regions were defined as S1, S2, and S3 from northwest to southeast (Table 1). S1 is close to Urumqi city and has three pipeline projects involved: the West-East Gas Pipeline I (WEGP I); WestEast Gas Pipeline II (WEGP II); and, the WCOP. S2 is near Wuzhong city where the WEGP II pipeline passes through. S3 is located in Yanchuan County and the WEGP I pipeline is there. The basic information of these three regions was presented in Table 1. Vegetation in these regions was severely disturbed during pipeline construction. These regions have different climates, soil types, and plant communities (Table 1). S1 and S2 are located in arid desert steppe region with low precipitation, and S3 is located in semi-humid area of the Chinese Loess Plateau. The environmental conditions
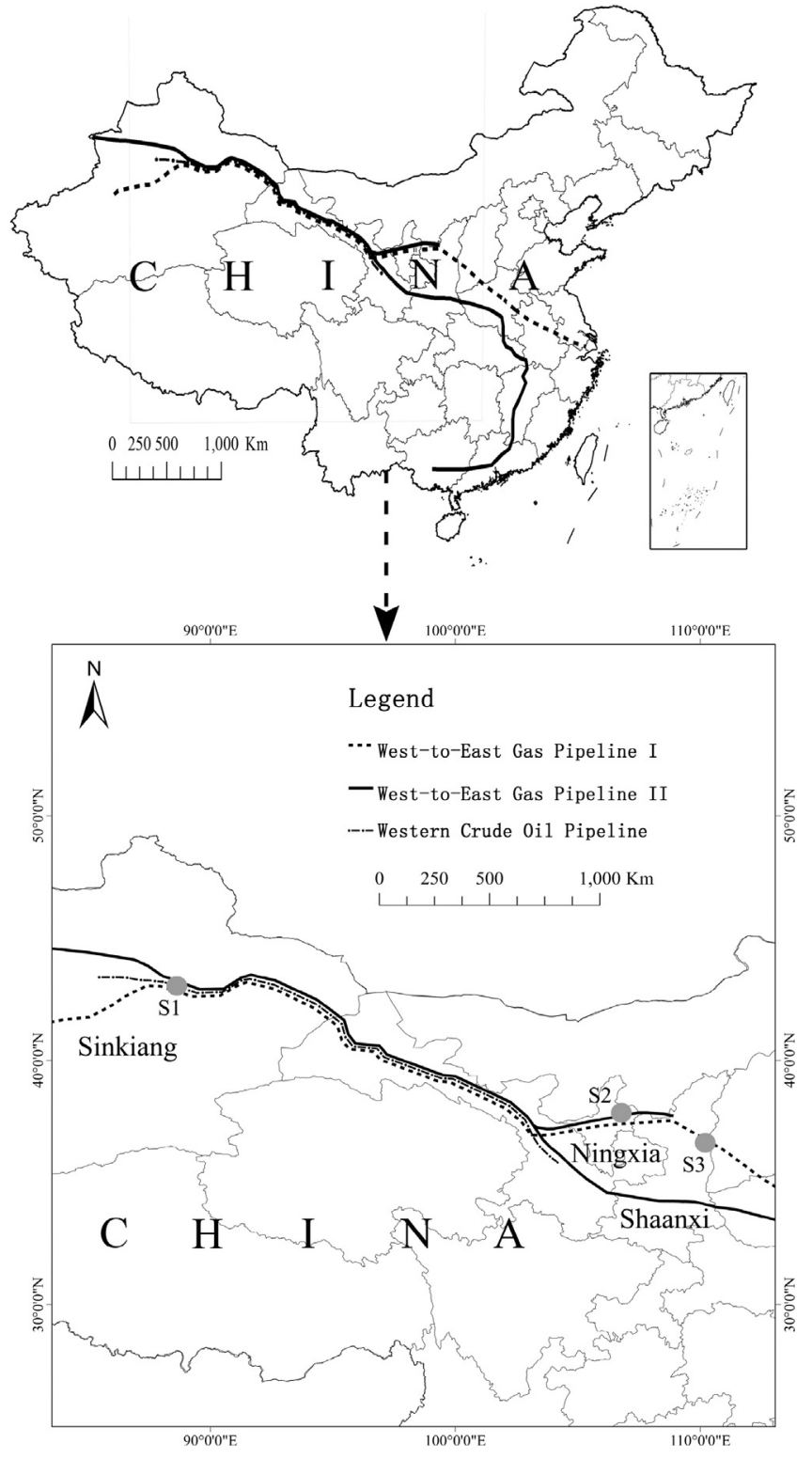

Fig. 1. Location of the study areas.

and dominant plant species are significantly different in three regions. The predominant plant species in S1 are Anabasis aphylla L., Stipa gobica Roshev., Artemisia frigida Willd. Sp. Pl., and Caragana leucophloea Pojark. In S2, Cleistogenes caespitosa Keng, Peganum harmala L., S. gobica Roshev. are primary species. Lespedeza davurica (Laxm.) Schindl., Metaplexis japonica (Thunb.) Makino, and associated species, including xylophyta, such as Periploca sepium Bung. and Ziziphus jujuba Mill., dominate the S3.

Table 1

General information of the study areas.

\begin{tabular}{|c|c|c|c|c|c|c|c|c|c|c|c|c|c|}
\hline Region & $\begin{array}{l}\text { Pipeline } \\
\text { project(s) } \\
\text { involved }\end{array}$ & $\begin{array}{l}\text { Elevation } \\
(\mathrm{m})\end{array}$ & $\begin{array}{l}\text { Years of } \\
\text { recovery } \\
\text { (years) }\end{array}$ & $\begin{array}{l}\text { Rainfall } \\
(\mathrm{mm})\end{array}$ & $\begin{array}{l}\text { Annual mean } \\
\text { temperature }( \\
\left.{ }^{\circ} \mathrm{C}\right)\end{array}$ & $\begin{array}{l}\text { Total sunshine } \\
\text { duration } \\
\text { (h) }\end{array}$ & $\begin{array}{l}\text { Precipitation } \\
\text { variability } \\
(\%)\end{array}$ & Soil type & $\mathrm{pH}$ & $\begin{array}{l}\text { SOM } \\
\left(\mathrm{g} \cdot \mathrm{kg}^{-1}\right)\end{array}$ & $\mathrm{TN}$ & TP & TK \\
\hline S1 & $\begin{array}{l}\text { WEGP I, WEGP } \\
\text { II, WCOP }\end{array}$ & 1180 & 3 & 235 & 7.14 & 2835.0 & 22 & $\begin{array}{l}\text { Calcic brown } \\
\text { soil }\end{array}$ & 8.67 & 14.77 & 0.72 & 0.75 & 17.01 \\
\hline $\mathrm{S} 2$ & WEGP II & 1323 & 3 & 211 & 8.8 & 2933.7 & 26 & Sierozem soil & 8.88 & 5.99 & 0.54 & 0.37 & 15.50 \\
\hline S3 & WEGP I & 1348 & 10 & 488 & 10.6 & 2558.6 & 21 & Loessal soil & 8.29 & 8.94 & 0.91 & 0.59 & 17.25 \\
\hline
\end{tabular}

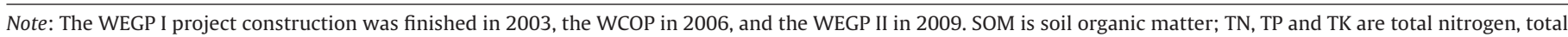
phosphorus, and total potassium in the soil, respectively. 

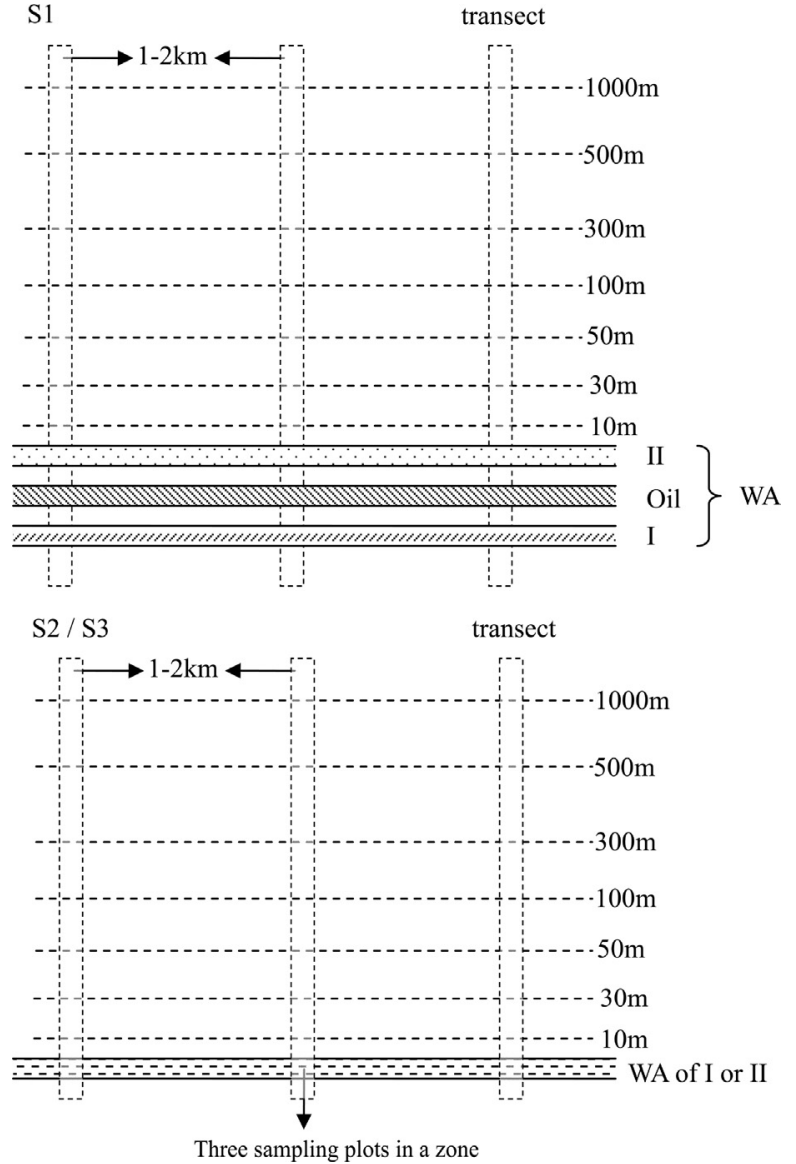

Fig. 2. Sampling sites and field experiment design in this study note: three pipelines in S1 were evaluated as a single working area (WA), but buffer zones were still set on every pipeline projection (WEGP I, WEGP II, and WCOP). Thus, WA of S1 had 18 more sampling plots than S2 and S3.

We investigated vegetation conditions during the operation period, when direct human disturbance decreased remarkably and vegetation recovery began. In this paper, this period was referred to as the "recovery period." The vegetation recovery in three regions was a natural recovery process without human-introduced restoration methods. From the completion of pipeline projects, natural recovery of vegetation lasts 3,3 , and 10 years in S1, S2, and S3, respectively.

\subsection{Field experiment design}

In S1, S2, and S3, buffers at $10 \mathrm{~m}, 30 \mathrm{~m}, 50 \mathrm{~m}, 100 \mathrm{~m}, 300 \mathrm{~m}$, $500 \mathrm{~m}, 800 \mathrm{~m}$, and $1000 \mathrm{~m}$ parallel to the pipelines in north side, and three transects approximately $1-2 \mathrm{~km}$ apart perpendicular to the pipelines were established. Sampling plots of $2 \times 2 \mathrm{~m}$ were established at each crossing site (Fig. 2). At each site, three plots were randomly selected at each distance. Since there are three pipelines in S1, the working areas of these pipelines were combined as one for field experiment design. In this study, the pipeline projects were labeled to I, Oil, and II according to the name of WEGP I, WCOP, and WEGP II.

Vegetation investigations along the pipelines were conducted during the growth season in late July and early August of 2013. The vegetation condition in undisturbed areas (at least six plots in each region) was investigated as a control. In total, 90 plots in $\mathrm{S} 1,72$ plots in S2 and S3 were investigated. The size of sampling plots in each region was large enough to represent the vegetation in their respective regions accurately.

\subsection{Data acquisition and processing}

The indices used in this study include vegetation coverage, Shannon-Wiener diversity index (SHDI), Pielou's evenness index (EVENNESS), Margalef's richness index (RICHNESS), and Sorensen's similarity coefficient (SC) (Eq.1-4). SHDI is used in community ecology to summarize the biodiversity of plants in a region. EVENNESS represents the uniformity, and RICHNESS indicates the species richness in a region (Ma, Zhang, Zhang, \& Li, 2012b). SC reflects the changes of the vegetation composition in a plot. Because calculating $\mathrm{SC}$ requires a large number of sample sizes, we combined the data from all the three sampling plots in each transect. These indices were used to calculate the comprehensive vegetation index (VI) which is designated to define the processes of vegetation recovery in each region (Cortina et al., 2006).

$$
\begin{aligned}
& \text { SHDI }=-\sum_{i=1}^{s}\left[\frac{(n i)}{(N)} \lg \frac{(n i)}{(N)}\right] \\
& \text { EVENNESS }=-\sum_{i=1}^{s}\left[\frac{(n i)}{(N)} \lg \frac{(n i)}{(N)}\right] / \ln S \\
& \text { RICHNESS }=\frac{(S-1)}{\ln N} \\
& \text { SC }=\frac{2 c}{(a+b)}
\end{aligned}
$$

where $i=1,2, \ldots S$; it stands for all the species in a plot; $S$ is the number of species; $N$ is the sum of the numbers of all species in a plot; $n i$ is the number of ith species in a plot; $c$ is the number of species that appear in both a plot and control area; $a$ and $b$ are the number of species that appear in the plot and the control, respectively.

Previous studies have shown that human disturbance has little influence on, or even helps keep high diversity levels (as shown with increases in the SHDI after disturbance events) (Brown, Ernest, Parody, \& Haskell, 2001; Schnoor \& Olsson, 2010; Gourlet-Fleury et al., 2013). Consequently, the situation of vegetation recovery cannot be evaluated solely by SHDI. Therefore, vegetation coverage, EVENNESS, RICHNESS, and SC were combined to develop the VI to reflect the vegetation recovery since the individual indices were often used to describe various aspects of the plant community (Magurran, 1988). However, SHDI was also used in RDA to analyze its relationship with engineering and environmental factors. These indices were normalized by deviation standardization and then multiplied by their weight to calculate the VI of each plot (Eq. 5). The weight of each index was determined by using entropy method, which is a quantitative and objective method in assigning weight (Xiao, Wang, Shi, Yang, \& Chen, 2014).

$Q\left(x_{\mathrm{ij}}\right)=\frac{\left(x_{\mathrm{ij}}-x_{\mathrm{imin}}\right)}{\left(x_{\mathrm{imax}}-x_{\mathrm{imin}}\right)}$

where $i=1,2, \ldots, \mathrm{n}$ stands for the concerned object set; $j=1,2, \ldots, \mathrm{m}$ is for the assessment indicator set; $X_{\mathrm{ij}}$ is the measured value from the $i$ th object for the $j$ th indicator; $Q\left(X_{\mathrm{ij}}\right)$ is the indicator score; and $X_{\mathrm{imin}}$ and $X_{\text {imax }}$ are the minimum and maximum values, respectively. If one of the values equaled 0 , we replaced it with 0.00001 for the next step.

A relative weight that reflected the degree of each indicator was used in this study. The new weight was modified by combining the subjective weight and the entropy coefficient (Eqs. 6-9). VI was derived by multiplying the weighted factors and the membership functions in Eq. 10 (Xiao et al., 2014).

$P_{\mathrm{ij}}=\frac{Q\left(x_{\mathrm{ij}}\right)}{\sum_{i=1}^{n} x_{\mathrm{ij}}}$ 
$e_{\mathrm{j}}=\frac{(-1)}{(\ln n)} \sum_{i=1}^{n} P_{\mathrm{ij}} \ln P_{\mathrm{ij}}$

$d_{\mathrm{j}}=1-e_{\mathrm{j}}$

$w_{\mathrm{j}}=\frac{d_{\mathrm{j}}}{\sum_{i=1}^{n} d_{\mathrm{j}}}$

$\mathrm{VI}=\sum_{j=1}^{n} w_{\mathrm{j}} \cdot Q\left(x_{\mathrm{j}}\right)$

where $P_{\mathrm{ij}}$ is the proportion of $X_{\mathrm{ij}}$ in the amount of an indicator; $e_{\mathrm{i}}$ is the entropy coefficient of the $j$ th indicator; $d_{\mathrm{j}}$ is the information value of the $j$ th indicator; and $w_{\mathrm{j}}$ is the weight of the $j$ th indicator.

We considered the controls to be part of these calculations, which were assigned a ratio of $\mathrm{VI}\left(\mathrm{VI}_{\mathrm{r}}\right)$. This enabled us to assess the vegetation recovery condition relative to full recovery and to compare recovery patterns across different regions. We refer to this index as the "ratio of recovery." The ratio of recovery was then analyzed using a one-way analysis of variance (ANOVA) to assess the variation in ratios of recovery at different distances from the pipeline. The condition of recovery at each distance from the pipeline was obtained by comparing the change in $\mathrm{VI}_{\mathrm{r}}$. The value of $\mathrm{VI}_{\mathrm{r}}$ was obtained by Eq. 11 .

$\mathrm{Vl}_{\mathrm{ri}}=\frac{\mathrm{Vl}_{\mathrm{i}}}{\mathrm{Vl}_{\mathrm{ck}}}$

where $\mathrm{VI}_{\mathrm{i}}$ is the value of the vegetation index in plot $\mathrm{I}, \mathrm{VI}_{\mathrm{ri}}$ is the ratio of the vegetation index in plot $\mathrm{I}$, and $\mathrm{VI}_{\mathrm{ck}}$ is the value of the vegetation index in the control plots.

To ensure the values of vegetation indices from different regions were comparable, the ratios of the four vegetation indices (vegetation coverage, EVENNESS, RICHNESS, and SC) were calculated using Eq. 12.

$R_{\mathrm{i}}^{\prime}=\frac{\left(R_{\mathrm{i}}-R_{\mathrm{ck}}\right)}{R_{\mathrm{ck}}}$

where $R_{\mathrm{i}}$ is the value of one vegetation index in plot $\mathrm{i} ; R_{\mathrm{i}}{ }^{\prime}$ is the ratio value of $R_{\mathrm{i}}$; and $R_{\mathrm{ck}}$ is the value of this index in the control plot. This transformation assigned the value zero to the control, and most of the buffer zones were negative. This visual representation aids in the identification of the recovery condition.

\subsection{Redundancy analysis}

The detrended correspondence analysis (DCA) was conducted to determine if a linear or unimodal model should be used for further analysis. DCA calculates the gradient length for each environmental factor related to vegetation recovery. A linear model should be used when the gradient is below 3; otherwise, a unimodal model is appropriate (González, Pignata, \& Orellana, 2003). The DCA calculated gradient lengths of $0.311,0.173,0.098$, and 0.129 form 1 st to 4 th gradient; thus, the linear model was selected. As a combination of ordination and multiple regression analyses, RDA is a variant of the basic linear transformation (Zhu et al., 2014). The affecting factors were evaluated by RDA using the Canoco program (Braak \& Šmilauer, 2002).

Total sunshine duration, precipitation variability, distance from pipeline (distance), years of recovery (which means the exact number of years between when the pipeline was finished and the year we began investigations), soil type, annual mean temperature, and rainfall were selected to explore the relationship between affecting factors and vegetation condition in RDA. The factors affecting vegetation recovery were divided into two categories: environmental factors; and, engineering factors. Total sunshine duration, precipitation variability, annual mean temperature, and rainfall which were environmental factors, were obtained from regional statistic yearbooks and were calculated based on annual averages from 2003 to 2013 (Table 1). Years of recovery and distance data collected in our field investigation were defined as engineering factors because they were related to engineering projects. Soil types in three regions were selected in RDA as three different codes $(1,2$, and 3 , representing calcic brown soil in S1, sierozem soil in S2, and loessal soil in S3, respectively). Vegetation condition was represented by the indices of coverage (vegetation coverage), SHDI, RICHNESS, EVENNESS, and SC. These indices were calculated by data obtained by field investigation in 2013. Indices used to represent soil quality included $\mathrm{pH}$, total nitrogen (TN), total phosphorus (TP), total potassium (TK), and soil organic matter (SOM), which were acquired from laboratory analyses of soil samples collected at a depth of $0-20 \mathrm{~cm}$ in each plot (Table 1). The soil nutrient of topsoil was not used in this study because it was likely to be highly affected by environmental factors. A Monte Carlo permutation test was used to test the significance. The criteria for the explanatory variables in the model were set to $p \leq 0.05$. The resulting ordination diagrams were produced using the CanoDraw program (Braak \& Šmilauer, 2002).

\section{Results}

\subsection{Comparison of the vegetation indices between different buffers}

The vegetation coverage, EVENNESS, RICHNESS and SC showed similar pattern, which has lower values in both working areas and $10 \mathrm{~m}$ buffer zone, and increased gradually with increasing distance from the pipelines (Fig. 3). However, EVENNESS showed a slightly different pattern, with a fluctuating increase as distance from the pipeline increased.

Results of this study showed that the lowest values of four vegetation indices were at the $10 \mathrm{~m}$ zone in $\mathrm{S} 1$. The change in vegetation coverage across the zones in S2 and S1 did not vary as much as it did in S1. The vegetation coverage became smooth beyond the $30 \mathrm{~m}$ zone in S2 and the $10 \mathrm{~m}$ zone in S3. EVENNESS values were close together, but fluctuated greatly, and were higher than EVENNESS values in some of the control zones. RICHNESS values in S1 were highest in the working area but decreased in the $10 \mathrm{~m}$ zone. There was a gradual increase across the other buffers and this trend was similar to the trend for RICHNESS in S3. The lowest values in the $10 \mathrm{~m}$ zone in $\mathrm{S} 1$ showed a significant difference from values in the control. Although the $1000 \mathrm{~m}$ zone obtained recovery, the value of RICHNESS within this zone remained lower than the value in the control. SC in S2 increased slightly across the buffer zones and was consistently lower than in S3. SC was also lower in S2 than in S1, beyond the $100 \mathrm{~m}$ zone.

\subsection{Ratio of recovery in different regions}

The vegetation recovery condition in three regions showed a clear trend of an initial decrease in the working area followed by a gradual increase to $1000 \mathrm{~m}$ from the pipeline in Fig. 4. However, there existed differences between the three regions. Vegetation recovery was lowest in $10 \mathrm{~m}$ zone, and then increased from the $30 \mathrm{~m}$ to $1000 \mathrm{~m}$ zone. The buffers beyond $300 \mathrm{~m}$ in S1 were not significantly $(p<0.05)$ different from conditions in the control, while vegetation conditions were significantly different from those in the $50 \mathrm{~m}$ and $30 \mathrm{~m}$ zones in S2 and S3, respectively. Thus, full-recovery was attained beyond the $300 \mathrm{~m}$ zone in S1, while in S2 and S3, it was attained beyond the $50 \mathrm{~m}$ and $30 \mathrm{~m}$ buffer zones. The highest $\mathrm{VI}_{\mathrm{r}}$ was found in the working area of S1, exhibiting the obvious effect of reduction in human disturbances. In addition, the ratio of recovery 

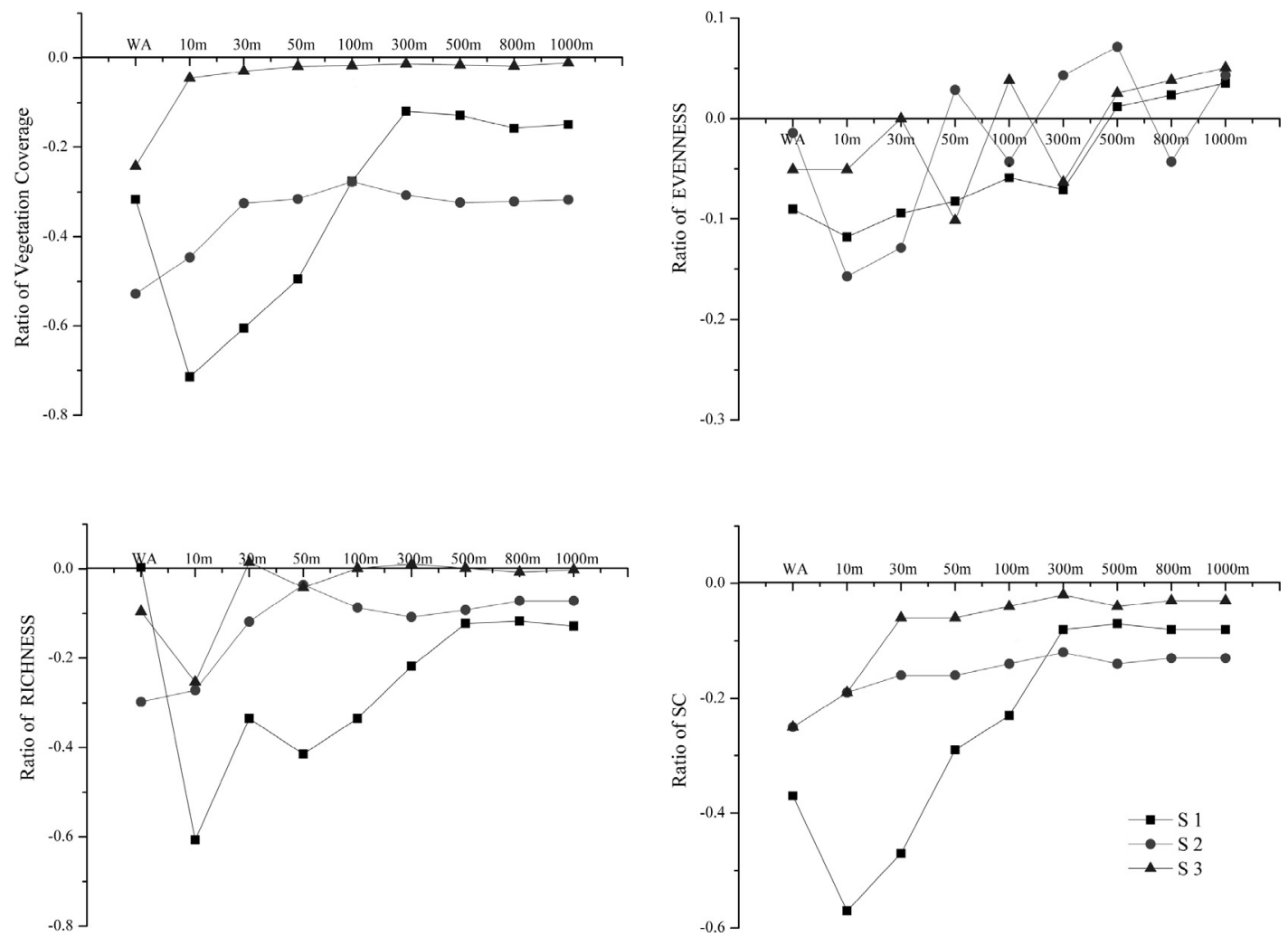

Fig. 3. Ratio of indices in different zones Note: Ratio of some index is the relative value compared by the CK in the figure. EVENNESS is Pielou's evenness index; RICHNESS is Margalef's richness index; SC is Sorensen's similarity coefficient.

of the working area in S2 was still low and close to the $10 \mathrm{~m}$ zone in S2 after three years of natural recovery.

\subsection{Main factors affecting vegetation recovery in the different regions}

Results of RDA indicated that distance, years of recovery, rainfall, annual mean temperature, and soil type were all positively correlated with the vegetation indices ( $p \leq 0.05$, Fig. 5$)$. The distance had a strong positive correlation with SC and RICHNESS, and years of recovery was positively correlated to SHDI. Vegetation coverage and evenness were positive related rainfall. The soil type and annual mean temperature were strongly related to each other, suggesting that they have similar effects on vegetation recovery. Total sunshine duration and precipitation variability were negatively correlated with vegetation indices. Moreover, total sunshine duration had a large negative influence on all vegetation indices. All of the plots had a regular distribution in RDA, which reflects the belt transect sampling method in this study. In Fig. 5, plots of the same region are linked to a line, called sampling-point-linked lines, which are parallel to the arrow of distance. These lines are perpendicular to the arrows of most of the environmental factors, which perhaps helps exploring the effects of these factors. Rainfall has an almost $90^{\circ}$ degree angle to the three lines, showing that it plays a more important role in determining vegetation recovery in three regions than other environmental factors.

All of the variables combined in RDA explained $82.2 \%$ of the variation in vegetation recovery, which indicates that the selected variables were the main factors affecting vegetation recovery. Rainfall on its own explained $16.3 \%(p<0.05)$ of the variation, and total sunshine duration explained $15.6 \%(p<0.05)$. Both of these values are higher than the variation explained by the other factors. The other indices were not significant according to a Monte Carlo permutation test $(p<0.05)$.
Based on RDA of soil quality and vegetation indices, all of the soil variables together explained $62.9 \%$ of the variation within vegetation indices (Fig. 6). SOM played a more important role in affecting the vegetation indices than other soil variables, in particular vegetation coverage. Increasing $\mathrm{pH}$ had a negative effect on vegetation recovery, and TN had a largely positive influence on SHDI. None of the soil variables were significantly related to vegetation indices according to Monte Carlo permutation test.

\section{Discussion}

\subsection{Buffer analyses of recovery condition}

\subsubsection{Characteristic analysis of each index}

Based on vegetation coverage, the vegetation condition in S1 was particularly poor, especially in buffers close to pipelines. This is possibly a result of multiple pipeline construction projects within this region (Atkinson \& Canter, 2011). The vegetation restoration processes of this region would have been interrupted by the next pipeline project after only 1 or 2 years. Frequent construction therefore may have hindered vegetation coverage recovery. This cumulative effect extended to the zones up to $100 \mathrm{~m}$ buffer zones from the working area of the pipeline. S2 experienced a relatively short recovery period and vegetation coverage condition in this area was worse than S3. In S3, the area with lowest vegetation recovery was just above the pipeline, which may be due to a concentration of human disturbance in this zone.

EVENNESS and RICHNESS calculations reflected the stability of the plant community (Maestre, Cortina, \& Vallejo, 2006). Evenness could reflect the distribution of species within a plant community and its values and patterns of variation differ from the indices that represent the state of recovery (Gosselin, 2006). EVENNESS in the studied regions was similar, but with a wide range. The variations in RICHNESS between the study areas were similar to the variations 

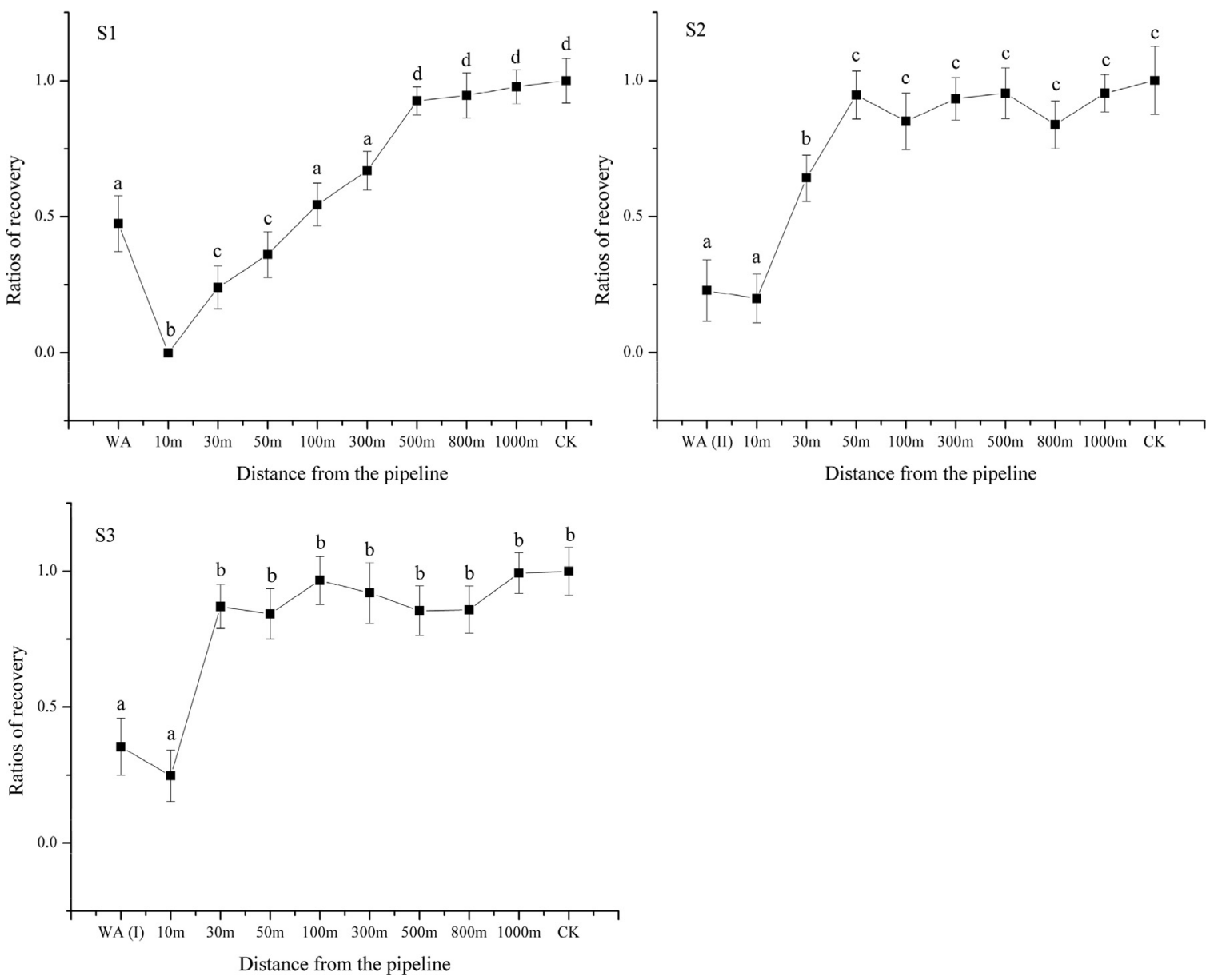

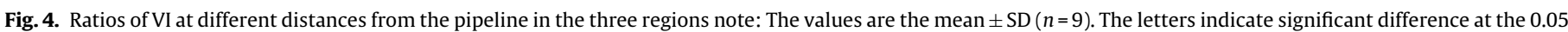

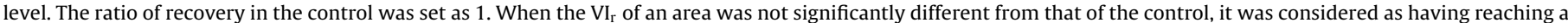
state of full recovery.

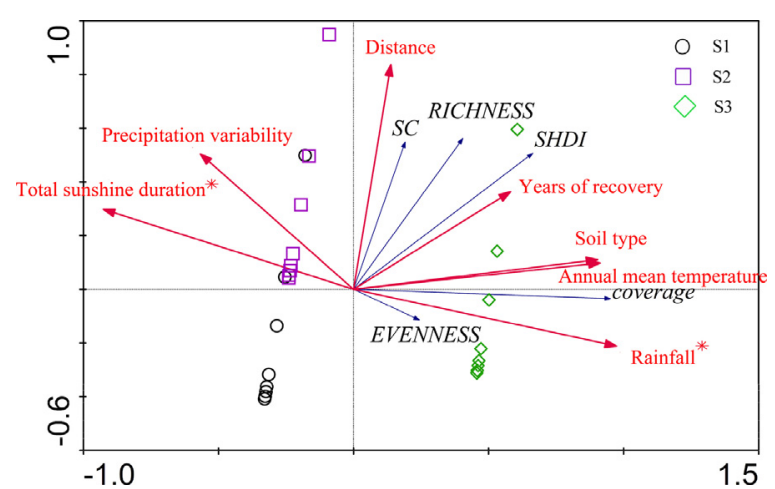

Fig. 5. RDA of the vegetation indices and their affecting factors Note: Abbreviations of affecting factors are as follows: abbreviations of vegetation indices are as follows: EVENNESS is Pielou's evenness index; coverage is vegetation coverage, SHDI is Shannon-Wiener diversity index; RICHNESS is Margalef's richness index; SC is Sorensen's similarity coefficient. The dots in this figure are the plots in the three areas respectively.

in vegetation coverage. The richness of plant increased obviously in the area within $30 \mathrm{~m}$ of the pipeline, which may indicate an edge effect between the construction area and natural environment (Hardt et al., 2013; Solé-Senan et al., 2014).

Large decrease of SC was the result of high-level human disturbance on the working area and $10 \mathrm{~m}$ buffer zone during the period of pipeline construction. Human disturbance removes local plants and may bring alien species to the construction areas,

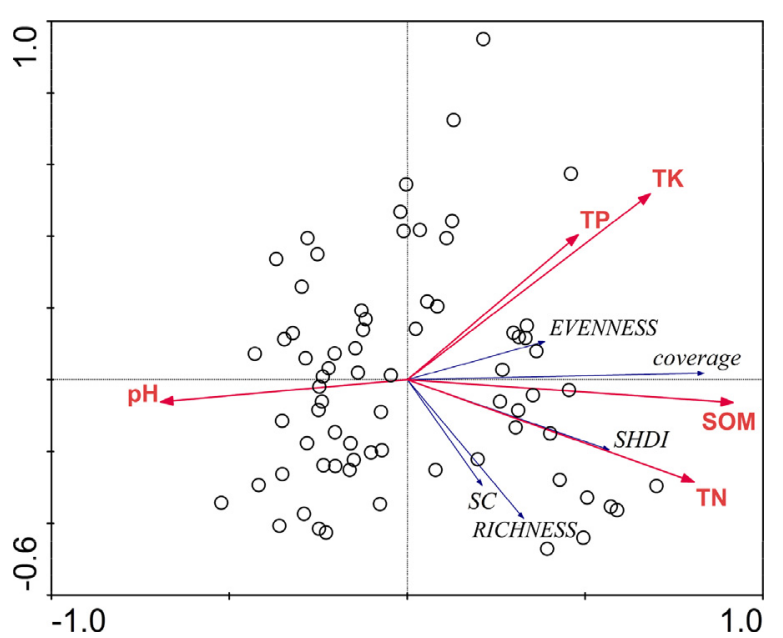

Fig. 6. Relationship between soil quality and the vegetation indices Note: SOM is soil organic matter; TN, TP and TK are total nitrogen, total phosphorus, and total potassium in soil, respectively. The dots are the plots in the three area.

which could alter the structure of local plant community (Zink, Allen, HeindlTenhunen, \& Allen, 1995; Petherbridge, 2000; Elsinger, 2009). It is difficult for an ecosystem to recover completely from this type of disturbance (Desserud et al., 2010). In S1, the SC of the working area was higher than the zones that were $10 \mathrm{~m}$ and $30 \mathrm{~m}$ from the pipeline. This may be due to the cumulative effect on the 
$10 \mathrm{~m}$ and $30 \mathrm{~m}$ buffer zone in this region (Cooper \& Sheate, 2002; Atkinson \& Canter, 2011). The working areas of the earlier pipeline projects had already started the processes of vegetation recovery and plant community succession. Therefore, in S1, the long recovery periods in the areas of WEGP I and WCOP resulted in high SC values, reflecting overall improved vegetation recovery within the working area. This reason could also explain why some of other indices in S1 showed values different from those in the other regions. For example, vegetation coverage, richness, and evenness were higher in the working area of S1 than S2.

\subsubsection{Recovery condition of the buffers in each region}

There were significant differences in the composition and structure of the plant communities between the working areas and their adjacent areas. This was consistent with previous studies (Feng, Li, Zhang, Li, \& Su, 2012). The vegetation differences between these regions reflected the disturbance effects of different engineering methods. The region had multiple pipelines and experienced relatively low recovery level, which increased the required time to attain full recovery. S1 was in recovery for the same duration as $\mathrm{S} 2$, but has relatively lower $\mathrm{VI}_{\mathrm{r}}$ value. Longer recovery periods are necessary to achieve increased recovery. In S3, the period of natural recovery took 10 years and attained full recovery, except in the working area and $10 \mathrm{~m}$ buffer zone (which was affected by accompanying road). However, in S1 and S2, where the recovery periods were only three years, only the areas $50 \mathrm{~m}$ or more from the pipeline recovered to their original condition.

The $10 \mathrm{~m}$ buffer zones had the lowest $\mathrm{VI}_{\mathrm{r}}$ in all three regions, although the plant community and soil properties in the working area had the higher disturbance levels during construction. Disturbance in this zone frequently continues even during the recovery period, because the $10 \mathrm{~m}$ buffer zones often contains the accompanying road (Shi, Xiao, Wang, \& Chen, 2014). In addition, the zone $10 \mathrm{~m}$ from the pipeline often undergoes few human-introduced restorative measures. In contrast, the working areas receive special protection from excavating and vehicular traffic during the recovery period (Desserud et al., 2010). Therefore, the zone $10 \mathrm{~m}$ from the pipeline is a key area that needs restoration attention during the recovery period.

\subsection{Analysis of the factors affecting vegetation recovery}

\subsubsection{Effects of environmental factors on vegetation recovery}

The results of RDA showed that rainfall had a significant influence on differences levels of vegetation recovery in three regions. This indicated that rainfall is one of key factors affecting vegetation recovery in semi-arid and arid regions (Bayramov et al., 2011; Fehmi \& Kong 2012). Additionally, the arrow direction in RDA indicates that rainfall was a main factor affecting vegetation indices, particularly vegetation coverage. Rainfall was the main factor that explained the distribution of sampling points in the RDA. The sampling points in S1 and S2 are close because of similar rainfall patterns in these two regions. The positive effect of annual mean temperature indicated a high-accumulated temperature. In terrestrial ecosystems, elevated accumulated temperature usually enhances photosynthesis and respiration, which accelerates plant growth (Phipps, Fulford, \& Crofts, 1974; Brown, de Beurs, \& Marshall, 2012). The total sunshine duration and precipitation variability were negatively correlated with vegetation coverage. Long hours of sunshine led to a high evaporation capacity, or potential evaporation (Goyal, Bharti, Quilty, Adamowski, \& Pandey, 2014), and increased water stress. This stress drove xerophytes to become the dominant plants in the community, potentially decreasing the total vegetation coverage. The negative effect of precipitation variability implied that a higher temporal variability of rainfall disturbed the process of species succession (Alday, Marrs,
\& Martínez-Ruiz, 2010), and could lead to a slower or incomplete recovery. Differences in soil properties also affected the vegetation coverage. In S3, sierozem soil and calcic brown soil had similar effects on vegetation recovery, but their effects on vegetation recovery were slower than loessal soil. In addition, the SOM and total amount of nutrition elements in the soil were positively correlated with plant growth (Fu, Liu, Ma, \& Zhu, 2004; Zuo et al., 2008; Liu et al., 2012a,b). Given that most of the soil in western China is alkaline (Yu et al., 2010), a high pH may cause land salinization and hamper vegetation recovery.

\subsubsection{Effects of the engineering method on vegetation recovery}

Both years of recovery and distance had important effects on vegetation recovery. The years of recovery was positively correlated with all of vegetation indices and had a close relation with SHDI, RICHNESS, and SC, which indicated that a long recovery period allowed sufficient time for species succession (Lebrija-Trejos, Meave, Poorter, Pérez-García, \& Bongers, 2010; Koch, Scheriau, Schupfner, \& Bernhardt, 2011). Species succession allows for a high diversity and richness, enabling the structure of the plant community to return to near its original state.

The RDA showed that distance was correlated with SC, richness, and SHDI. In all three regions, the areas $300 \mathrm{~m}$ away from the pipelines had similar species structures to those of the control areas. Holding the other conditions constant, vegetation recovery increased and the vegetation indices increased and became more stable with greater distance from the pipeline project. This trend indicated the decreasing of human disturbance in areas farther away from the pipeline. Moreover, the direction of this arrow was parallel to the three sampling-point-linked lines, which showed that distance had the same effect in each area, with little spatial variation.

\subsubsection{Differences between environmental and engineering factors}

Results of this study showed that rainfall played relatively a more important role in affecting vegetation recovery than other environmental factors, and the years of recovery was also important in vegetation recovery as an engineering factor. Because vegetation recovery in a same region is influenced by the same environmental factors, such as rainfall and temperature, the effects of environmental factors of vegetation recovery could be clearly identified at large-scale comparisons. In addition, there were almost no regional differences in the effects of engineering factors on vegetation recovery.

The area close to pipeline had the highest disturbance levels. Although this area was also affected by environmental factors (such as rainfall, temperature, and soil properties), vegetation recovery in areas close to pipeline was more prone to be dominated by engineering factors. However, in areas that were $300 \mathrm{~m}$ or farther from the pipeline, the vegetation indices were similar to the control and the vegetation conditions were close to pre-disturbance levels. The process of vegetation recovery in areas farther from pipeline was dominated by environmental factors. In contrast, the area within $300 \mathrm{~m}$ of pipeline, engineering factors predominately determined the levels of vegetation recovery.

Based on the results of this study, human-introduced measures were suggested to promote vegetation recovery process during the recovery period. Based on the fact that environmental factors are the most important factors in determining the degree of vegetation recovery, improving the environmental conditions would increase vegetation recovery rates. For example, supplemental watering in areas with little rainfall could help to achieve increasing vegetation recovery rates. However, in areas where engineering factors are dominant, appropriate measures to adjust engineering factors, such as reducing human disturbance (McMahon et al., 2008b) or planting local plants, would be more helpful for improving vege- 
tation recovery (Hann et al., 2005; Desserud \& Naeth, 2013, 2014). The zone $10 \mathrm{~m}$ from the pipeline had the worst vegetation recovery rates and can be considered as a critical zone in vegetation recovery than other zone.

\section{Conclusions}

A consistent general pattern of vegetation recovery along the pipeline project has been found. The buffer zone of $0-10 \mathrm{~m}$ from the working area was often disturbed by the accompanying road, which inhibited vegetation recovery and resulted in the highest levels of vegetation disturbance. Outside $10 \mathrm{~m}$ zone, the vegetation recovery gradually increased with increasing distance from the pipeline. The $10 \mathrm{~m}$ area presented as critical zone for postconstruction recovery measures. The rainfall was an important factor affecting vegetation recovery. Other environmental factors (such as total sunshine duration, and soil quality) and engineering factors (such as years of recovery and distance) also influenced vegetation recovery rates. The engineering factors played dominant roles in shaping vegetation recovery within $300 \mathrm{~m}$ zones of the pipeline project, while environmental factors played more important roles in vegetation recovery beyond $300 \mathrm{~m}$. The $\mathrm{S} 3$ underwent 10 years of natural recovery, and it was reasonable to expect natural full recovery within 10 years after initial disturbance in mostly affected areas. However, the working area and accompanying road need more time or human-introduced measures to achieve full recovery. Appropriate watering of the area close to working area would be an appropriate measure to increase vegetation recovery rate. In areas without water stress, reducing human disturbance would be an appropriate way. Further study should provide a theoretical basis for ecological recovery in pipeline project areas, as well as determine specific protection measures and vegetation recovery processes suitable for different ecosystem types.

\section{Acknowledgment}

This work was supported by the Industry Research Project on Environmental Protection (201209029).

\section{References}

Alday, J. G., Marrs, R. H., \& Martínez-Ruiz, C. (2010). The importance of topography and climate on short-term revegetation of coal wastes in Spain. Ecological Engineering, 36, 579-585.

Andrews, A. (1992). Fragmentation of habitat by roads and utility corridors: a review. Biological Conservation, 59, 130-141

Atkinson, S. F., \& Canter, L. W. (2011). Assessing the cumulative effects of projects using geographic information systems. Environmental Impact Assessment Review, 31, 457-464

Bayramov, E., Buchroithner, M. F., \& McGurty, E. (2011). determination of main climate and ground factors controlling vegetation cover regrowth along oil and gas pipelines using multiple, spatial and geographically weighted regression procedures. Environmental Earth Sciences, 66, 2047-2062.

Braak, C. J. F., \& Šmilauer, P. (2002). Canoco reference manual and canodraw for windows user's guide: software for canonical community ordination (version 4.5). New York: Microcomputer Power.

Bradshaw, A. (1997). Restoration of mined lands-using natural processes Ecological Engineering, 8, 255-269.

Brown, J. H., Ernest, S. K. M., Parody, J. M., \& Haskell, J. P. (2001). Regulation of diversity: maintenance of species richness in changing Environments. Oecologia, 126, 321-332.

Brown, M. E., de Beurs, K. M., \& Marshall, M. (2012). Global phenological response to climate change in crop areas using satellite remote sensing of vegetation, humidity and temperature over 26 years. Remote Sensing of Environment, 126, 174-183.

Chen, L., \& Gao, Q. (2006). Chance and challenge for china on ecosystem management: lessons from the west-to-east pipeline project construction. AMBIO: A Journal of the Human Environment, 35, 91-93.

Chen, L. D., Tian, H. Y., Zhang, X. Y., Feng, X. M., \& Yang, W. H. (2012). Public attitudes and perceptions to the west-to-east pipeline project and ecosystem management in large project construction. International Journal of Sustainable Development and World Ecology, 19, 219-228.
Cooper, L. M., \& Sheate, W. R. (2002). Cumulative effects assessment: a review of UK environmental impact statements. Environmental Impact Assessment Review, 22, 415-439.

Cortina, J., Maestre, F. T., Vallejo, R., Baeza, M. J., Valdecantos, A., \& Perez-Devesa, M. (2006). Ecosystem structure, function, and restoration success: are they related? Journal for Nature Conservation, 14, 152-160.

Desserud, P., Gates, C. C., Adams, B., \& Revel, R. D. (2010). Restoration of foothills rough fescue grassland following pipeline disturbance in southwestern Alberta. Journal of Environmental Management, 91, 2763-2770.

Desserud, P. A., \& Naeth, M. A. (2013). Natural recovery of rough fescue (festuca hallii (vasey) piper) grassland after disturbance by pipeline construction in central Alberta, Canada. Natural Areas Journal, 33, 91-98.

Desserud, P. A., \& Naeth, M. A. (2014). Predicting grassland recovery with a state and transition model in a natural area, central Alberta, Canada. Natural Areas Journal, 34, 429-442.

Egbunike, O. N., \& Potter, A. T. (2011). Are freight pipelines a pipe dream? a critical review of the UK and European perspective. Journal of Transport Geography, 19, 499-508.

Elsinger, M. (2009). Reclamation status of plains rough fescue grasslands at rumsey block in Central Alberta after oil and gas well site and pipeline disturbance. Edmonton (AB): University of Alberta.

Fehmi, J. S., \& Kong, T. M. (2012). Effects of soil type, rainfall, straw mulch, and fertilizer on semi-arid vegetation establishment, growth and diversity. Ecological Engineering, 44, 70-77.

Feng, L., Li, X. R., Zhang, J. G., Li, X. J., \& Su, J. O. (2012). Vegetation alteration in response to highway construction in the desertified steppe zone of the tengger desert, north China. Arid Land Research and Management, 26, 59-78.

Fu, B., Liu, S., Ma, K., \& Zhu, Y. (2004). Relationships between soil characteristics, topography and plant diversity in a heterogeneous deciduous broad-leaved forest near Beijing, China. Plant and Soil, 261, 47-54.

González, C. M., Pignata, M. L., \& Orellana, L. (2003). Applications of redundancy analysis for the detection of chemical response patterns to air pollution in Lichen. Science of the Total Environment, 312, 245-253.

Gosselin, F. (2006). An Assessment of the dependence of evenness indices on species richness. Journal of Theoretical Biology, 242, 591-597.

Gourlet-Fleury, S., Beina, D., Fayolle, A., Ouédraogo, D. Y., Mortier, F., Bénédet, F., Closset-Kopp, D., \& Decocq, G. (2013). Silvicultural disturbance has little impact on tree species diversity in a Central African moist forest. Forest Ecology and Management, 304, 322-332.

Goyal, M. K., Bharti, B., Quilty, J., Adamowski, J., \& Pandey, A. (2014). Modeling of daily pan evaporation in sub tropical climates using ann, ls-svr, fuzzy logic, and anfis. Expert Systems with Applications, 41, 5267-5276.

Hann, M., Morgan, R., Shilston, D., Mirtskhoulava, T. E., Nadirashvili, V., Gasca, A., Clarke, J., \& Sweeney, M. (2005). Vegetation establishment and management for the restoration of pipeline rights-of-way. Terrain and geohazard challenges facing onshore oil and gas pipelines, 67, 2-686.

Hardt, E., Pereira-Silva, E. F. L., Dos Santos, R. F., Tamashiro, J. Y., Ragazzi, S., \& Lins, D. B. d. S. (2013). The Influence of natural and anthropogenic landscapes on edge effects. Landscape and Urban Planning, 120, 59-69.

Hopmans, J. W., \& Dane, J. H. (1986). Temperature dependence of soil hydraulic properties. Soil Science Society of America Journal, 50, 4-9.

Howgego, T., \& Roe, M. (1998). The use of pipelines for the urban distribution of goods. Transport Policy, 5, 61-72.

Industry Research Center. (2014). China Oil and Gas Pipeline Construction Industry Indepth Research and Investment Strategy Report, 2013-2017. Qianzhan Business Information Co., Ltd (accessed online 9.24.14). http://en.qianzhan.com/report/ detail/f3036f859ab34586html

Ivey, J. L., \& McBride, R. A. (1999). Delineating the zone of topsoil disturbance around buried utilities on agricultural land. Land Degradation E Development, 10, 531-544.

Kambara, T., \& Howe, C. (2007). China and the global energy crisis: development and prospects for China's oil and natural gas. Cheltenham: Edward Elgar.

Koch, M. A., Scheriau, C., Schupfner, M., \& Bernhardt, K.-G. (2011). Long-term monitoring of the restoration and development of limestone grasslands in north western Germany: vegetation screening and soil seed bank analysis. Flora, 206, 52-65.

Lebrija-Trejos, E., Meave, J. A., Poorter, L., Pérez-García, E. A., \& Bongers, F. (2010). Pathways, mechanisms and predictability of vegetation change during tropical dry forest succession. Perspectives in Plant Ecology, Evolution and Systematics, $12,267-275$.

Liu, H., Noble, J. S., Wu, J., \& Zuniga, R. (1998). Economics of coal log pipeline for transporting coal. Transportation Research Part A: Policy and Practice, 32 377-391.

Liu, X., Zhang, W., Yang, F., Zhou, X., Liu, Z., Qu, F., Lian, S., Wang, C., \& Tang, X. (2012). Changes in vegetation-environment relationships over long-term natural restoration process in middle Taihang mountain of North China. Ecological Engineering, 49, 193-200.

Ma, C., Zhang, G., Zhang, X., Li, H., Ju, M., Zhou, B., \& Zhang, L. (2012). Modes of ecological restoration for wetlands in the Binhai new district of Tianjin. South-to-North Water Diversion and Water Science E' Technology, 10(4), 30-33 (in Chinese)

Ma, C., Zhang, G., Zhang, X., \& Li, Y. (2012). Application of multiple indicators in environment evaluation of coastal restoration engineering: a case study in Bohai Bay in China. In Proceedings of 2nd International Conference on Civil Engineering, Architecture and Building Materials (p. 2228). 
Ma, C., Zhang, X., Chen, W., Zhang, G., Duan, H., Ju, M., Li, H., \& Yang, Z. (2013). China's special marine protected area policy: trade-off between economic development and marine conservation. Ocean \& Coastal Management, 76, 1-11.

Maestre, F. T., Cortina, J., \& Vallejo, R. (2006). Are ecosystem composition, structure, and functional status related to restoration success? a test from semiarid mediterranean steppesecosystem composition, structure, and functional status related to restoration success? a test from semiarid mediterranean steppes. Restoration Ecology, 14, 258-266.

Magurran, A. E. (1988). Ecological Diversity and Its Measurement. pp. 7-47. Princeton: Princeton University Press.

Malizia, A., Chacoff, N. P., Grau, H. R., \& Brown, A. D. (2004). Vegetation recovery on a gas-pipeline track along an altitudinal gradient in the Argentinean Yungas forests. Ecologia Austral, 14, 165-178.

Martínez-Ruiz, C., Fernández-Santos, B., Putwain, P. D., \& Fernández-Gómez, M. J. (2007). Natural and man-induced revegetation on mining wastes: changes in the floristic composition during early succession. Ecological Engineering, 30, 286-294.

McMahon, S., Arnold, B., Powell, T., Welsh, G., \& Donnelly, M. (2008). Restoration on a Pipeline Right-of-Way in Red Rock Canyon National Conservation Area, Nevada. Pages 805-818. In J. W. Goodrich-Mahoney, L. P. Abrahamson, J. L. Ballard, \& S. M. Tikalsky (Eds.), Environment concerns in rights-of-way management 8th international symposium (pp. 805-818). Amsterdam: Elsevier.

McMahon, S., Arnold, B., Powell, T., Welsh, G., \& Smith, P. (2008). Desert Restoration on Pipeline Rights-of-Way. Pages 819-833. In J. W. Goodrich-Mahoney, L. P. Abrahamson, J. L. Ballard, \& S. M. Tikalsky (Eds.) Environment concerns in rights-of-way management 8th international symposium (pp. 819-833). Amsterdam: Elsevier.

Olson, E. R., \& Doherty, J. M. (2012). The legacy of pipeline installation on the soil and vegetation of southeast wisconsin wetlands. Ecological Engineering, 39, 53-62.

Petherbridge, W. (2000). Sod salvage and minimal disturbance pipeline reclamation techniques: implications for native prairie restoration. Edmonton, $\mathrm{AB}$ : Thesis University of Alberta.

Phipps, R., Fulford, R. J., \& Crofts, F. (1974). Relationships between the production of forage maize and accumulated temperature, Ontario heat units and solar radiation. Agricultural Meteorology, 14, 385-397.

Qi, S. S., Hao, F. H., Ouyang, W., \& Cheng, H. G. (2012). Characterizing landscape and soil erosion dynamics under pipeline interventions in Southwest China. Procedia Environmental Sciences, 13, 1863-1871.
Schnoor, T. K., \& Olsson, P. A. (2010). Effects of soil disturbance on plant diversity of calcareous grasslands. Agriculture, Ecosystems \& Environment, 139, 714-719.

Shi, P., Xiao, J., Wang, Y. F., \& Chen, L. D. (2014). The effects of pipeline construction disturbance on soil properties and restoration cycle. Environmental Monitoring and Assessment, 186, 1825-1835.

Solé-Senan, X. O., Juárez-Escario, A., Conesa, J. A., Torra, J., Royo-Esnal, A., \& Recasens, J. (2014). Plant diversity in mediterranean cereal fields: unraveling the effect of landscape complexity on rare arable plants. Agriculture, Ecosystems E' Environment, 185, 221-230.

Soon, Y. K., Arshad, M. A., Rice, W. A., \& Mills, P. (2000). Recovery of chemical and physical properties of boreal plain soils impacted by pipeline burial. Canadian Journal of Soil Science, 80, 489-497.

Twort, A., \& Rees, J. G. (2004). Civil Engineering Project Management (Fourth ed.)). London: Elsevier., pp: 225-235.

Wang, W., Xie, J., Li, Z., \& Zhu, J. (2010). Research on water \& soil conservation and eco-restoration management in west-east natural gas pipeline project of China. In Pages 808-811 in E-Business and E-Government (ICEE).

Xiao, J., Wang, Y. F., Shi, P., Yang, L., \& Chen, L. D. (2014). Potential effects of large linear pipeline construction on soil and vegetation in ecologically fragile regions. Environmental Monitoring and Assessment.

Yakovleva, N. (2011). Oil pipeline construction in Eastern Siberia: implications for indigenous people. Geoforum, 42, 708-719.

Yang, S.-Z., Jin, H.-J., Yu, S.-P., Chen, Y.-C., Hao, J.-Q., \& Zhai, Z.-Y. (2010). Environmental hazards and contingency plans along the proposed china-russia oil pipeline route, northeastern China. Cold Regions Science and Technology, 64, 271-278.

Yu, R., Liu, T., Xu, Y., Zhu, C., Zhang, Q., Qu, Z., Liu, X., \& Li, C. (2010). Analysis of salinization dynamics by remote sensing in hetao irrigation district of North China. Agricultural Water Management, 97, 1952-1960.

Zhu, H. D., Shi, Z. H., Fang, N. F., Wu, G. L., Guo, Z. L., \& Zhang, Y. (2014). Soil moisture response to environmental factors following precipitation events in a small catchment. Catena, 120, 73-80.

Zink, T. A., Allen, M. F., HeindlTenhunen, B., \& Allen, E. B. (1995). The effect of a disturbance corridor on an ecological reserve. Restoration Ecology, 3, 304-310.

Zuo, X., Zhao, H., Zhao, X., Guo, Y., Yun, J., Wang, S., \& Miyasaka, T. (2008). Vegetation pattern variation, soil degradation and their relationship along a grassland desertification gradient in horqin sandy land, northern China. Environmental Geology, 58, 1227-1237. 